\title{
TRANSLESBIANIZANDO O OLHAR: REPRESENTAÇÕES NA MARGEM DA ARTE
}

\author{
Lin Arruda \\ Universidade Federal de Santa Catarina
}

\begin{abstract}
Resumo: Reivindicando o fracasso, a inadequação, a marginalidade e a negatividade como prerrogativas distintivas dos projetos e das subjetividades dissidentes, o presente ensaio sugere que nas proposições contra-artísticas brasileiras "Pegadinha Les-Bi-Trans", "Sapatoons Queerdrinhos" e "Eu vejo lésbicas em todos os lugares" está sendo formulado um imaginário marginal lésbico/trans. A articulação de uma mirada translesbianizante capaz de desestabilizar as retóricas e visualidades da instituição heterocapitalista é aqui abordada como uma potencialidade das estratégias autorrepresentativas pós-identitárias e negativas empregadas em projetos que se situam às margens das instituições autorizadas de produção de conhecimento (dentre elas os sistemas das artes).
\end{abstract}

Palavras-chove: arte queer; representação; lesbiandade; transgeneridade; dissidência.

\section{Introdução}

O objetivo do presente ensaio é apresentar algumas ideias sobre proposições de lésbicas e/ou pessoas transgênero que se situam propositalmente fora dos sistemas das artes e com as quais me envolvi recentemente.

Nos últimos anos, acompanhei muitas galerias e museus brasileiros esforçando-se para suprir a demanda viral de mostras formadas exclusivamente por mulheres artistas - uma imprescindível e significativa exigência do momento histórico, do público e também do mercado e dos editais de arte. Excluindo raras exceções, a curadoria de muitas mostras brasileiras que enfocaram o tema "mulheres artistas" baseou-se no remanejamento de seu próprio acervo para organizar uma seleção pautada exclusivamente pelo gênero da artista. Apesar de funcionar para grandes instituições que já se comprometiam há algum tempo a incorporar obras de mulheres artistas e de artistas feministas nos seus acervos (como, por exemplo, o Centre Pompidou ou o MoMA), esse modelo importado de curadoria deixou a desejar em exposições como Mulheres, artistas e brasileiras (Salão Oeste do Palácio do

Copyright $\odot 2015$ by Revista Estudos Feministas. 
Planalto - DF), Mirada de gênero - a perspectiva feminina (MuMA, Curitiba), Mulheres nas Coleções João Sattamini (MAC, Niterói), Identidade feminina (coleção do acervo do IVAM exposta na Galeria Marta Traba do Memorial da América Latina) e muitas outras.

O principal desafio desse exercício não foi encontrar as artistas e as obras (afinal, elas sempre existiram, apesar de que tirá-las do fundo do acervo empoeirado não deve ter sido uma tarefa fácil para os/as estagiários/as), a maior dificuldade estava em produzir diálogos entre elas e organizar uma mostra coerente, uma vez que o recorte curatorial pautado pelo gênero (critério centrado no "sexo biológico") não garantia uma unidade temática consistente.'

Esse modelo, que geralmente organiza as obras segundo a cronologia da história da arte hegemônica (em especial da arte moderna brasileira), em vez de promover ruídos e instabilidades, sustenta alguns preceitos que a arte feminista e dissidente critica incisivamente: a fixidez da identidade, a inflexibilidade das categorias, o paternalismo (nesses casos, implícito na "celebração das mulheres") e a assimilação dentro de um sistema rígido e tradicional; ou seja, a intenção acomodativa e acolhedora dessas mostras não só ignora e silencia o fato de que sexo e gênero são a crise do século, mas também contraria as ideias de Griselda Pollock, ${ }^{2}$ uma das primeiras historiadoras a vislumbrar na interferência feminista uma quebra de paradigmas nas historiografias e nos sistemas das artes (como alternativa a simples e despotencializada incorporação de artistas mulheres nas mostras, nos catálogos, nos livros e na história tradicional e naturalizada da arte).

Nos casos dessas exposições, nem mesmo títulos que produzem a sensação ilusória de unidade (por exemplo, a previamente mencionada ldentidade feminina) ou o conteúdo dos textos dos catálogos das mostras conseguiam tapar os abismos que separavam uma obra de outra e disfarçar o aspecto retalhado e emendado da seleção organizada sob um critério descontínuo preguiçosamente submetido às buscas em base de dados do acervo (nesse caso, com o filtro "sexo").

Ironicamente, essas exposições que apostavam na crueza do gênero e no jargão "identidade feminina", "universo feminino", "sensibilidade feminina" ou "arte feita por mulheres" evidenciaram algo que a teoria feminista interseccional constatou algumas décadas atrás: não existe uma unidade (essencialista ou empírica) das mulheres que reúna uma experiência comum - e vale também dizer que, contrariando o desejo normativo e a matriz de inteligibilidade dos gêneros, nem todas as mulheres são femininas.

No mesmo sentido, acompanhei o trabalho de muitos/as pesquisadores/as e produtores/as culturais que, como eu, voltaram-se ao tema das assimetrias de gênero nos sistemas das artes e quebraram a cabeça para aplicar teoria, engajamento político e o rótulo de "feminista" às produções de mulheres artistas latino-americanas e caribenhas, apesar da resistência declarada de algumas delas. Afinal, onde estão as artistas feministas engajadas latino-americanas? A minha sugestão é que muitas proposições incisivas e criativas estão surgindo às margens das instituições que retêm a produção de conhecimento considerado legítimo e estão sendo elaboradas por pessoas localizadas também nas bordas do gênero, da sexualidade, do capitalismo, da família, da igreja, do trabalho, do estado, da escola e dos banheiros.

${ }^{1}$ Ao passo que exposições menores e de artistas contemporâneas promovem agrupamentostemáticos mais coerentes, como, por exemplo, a Corpos insurgentes do SESC Vila Mariana, que reúne 12 artistas que tangenciam o tema dos padrões estéticos impostos às mulheres.

${ }^{2}$ Em seu artigo Feminist Interventions in the Histories of Art, Pollock (1988) comenta e exemplifica a forma como são reproduzidas e perpetuadas as hierarquias e assimetrias de gênero na história da arte e nos demais sistemas das artes. Ao contrapor posicionamento a neutralidade no que diz respeito às assimetrias de gênero, Pollock defende uma quebra de paradigmas na historiografia da arte e oferece uma metodologia que desafia e desestabiliza os valores normativos no campo artístico. 
Neste ensaio não linear, pretendo sugerir que, à margem dos sistemas e dos aparatos ideológicos culturais, lésbicas e/ou pessoas trans, impulsionadas pelo ócio criativo, têm se contaminado e se agrupado em manadas afetivo-políticas autônomas para fazer piadas, brincadeiras, pegadinhas, pichações e manifestações criativas, incisivas e deliberadamente políticas. Os espaços expositivos que abrigam essa versão sombria de artista e de obra de arte são as ruas e as okupas, ${ }^{3}$ e, em vez de aparecerem em catálogos de exposição, essas proposições, quando registradas, circulam xerocadas em baixa qualidade em fanzines, como é o caso da publicação independente Eu vejo lésbicas em todos os lugares. ${ }^{4}$

Esse divertido fanzine apresenta o projeto fotográfico Paralélicas e um breve texto que discorre sobre a desestabilização do olhar heterocompulsivo. Trata-se de uma série de 9 fotos propositalmente fora de foco que confundem as perspectivas da cena retratada objetivando encaixar e situar no mesmo plano duas figuras que estão, na verdade, em dimensões distantes e que sequer se conhecem ou estão interagindo. O resultado desse recurso de enquadramento é uma série de retratos de lésbicas tocando-se afetuosamente (segurando as mãos, aproximando os rostos, acariciando-se e beijando-se), ou seja, a câmera formula e capta um universo paralelo em que todas e quaisquer mulheres são lésbicas.

Na foto Paralélicas \#3 (Figura 1), vemos ao centro duas senhoras que, sentadas na praça de alimentação de um shopping, aparentemente dão as mãos num gesto carinhoso e trocam olhares profundos e atentos. A proximidade de seus rostos, resultante do jogo de perspectivas, expressa intimidade e ternura mútua, viabilizando uma leitura lésbica dos corpos representados.

O universo paralelo em que essas pessoas aleatoriamente alinhadas (que podem ou não ser lésbicas) tocam-se e demonstram afeto em público é alternadamente dissolvido e remontado na imagem: embora as figuras das lésbicas sejam mais facilmente percebidas justamente por estarem no centro da composição, um olhar atento revela que as interações reais acontecem entre elas e as figuras dispostas nas extremidades da imagem.

Pode-se dizer que aqui a produção de significado proposto opera através de um recurso lesbianizante, ou seja, trata-se de um olhar que projeta lesbiandade em figuras que, independentemente de se identificarem ou não com essa identidade, no momento do ato fotográfico não estavam conscientes, consentida ou espontaneamente expressando-a (e possivelmente não aprovariam o resultado final). Essas imagens geram um repertório original de representações lésbicas porque se diferenciam de autorretratos ou de outras imagens de "lésbicas de verdade", como as que vemos, por exemplo, em algumas obras das artistas contemporâneas Cathy Opie, Cabello/Carcerer, Sarah Lucas e outras. Nesse sentido, pode-se dizer que as fotos da série Paralélicas infiltram-se, adentram e passam a constituir o imaginário lésbico e, nesse processo, expandem a categoria e dissolvem os estereótipos que a unificariam. Esse efeito é alcançado devido ao fato de que as figuras representadas não poderiam exprimir um ideal lésbico ("o que é" e "como se parece uma lésbica") porque são frutos de disposições circunstanciais de corpos relativamente aleatórios cuja identidade e "sexualidade" permanecem desconhecidas. Trata-se, portanto, de representações despretensiosas que, em vez de oferecerem limites acerca da categoria "lésbica", desestabilizam as verdades desse repertório imagético e desnaturalizam a ideia de que todas as pessoas são heterossexuais a menos que se prove o contrário.

Mais que popularizar ou estender imaginários lésbicos (ou seja, criar novas imagens de lésbicas), o projeto tangencia o tema da invisibilidade atentando para a importância de descolonizar o olhar: esse exercício fotográfico convida o/a espectador/a a ver lésbicas

${ }^{3}$ Ocupações ilegais e anarquistas de casas ou edifícios.

${ }^{4}$ Esse fanzine brasileiro é de autoria desconhecida e estima-se que tenha sido produzido em 2014. 
em todos os lugares, invertendo a lógica do olhar heterocêntrico que, forçosamente míope, enxerga primas, amigas, vizinhas e até irmãs gêmeas em amantes lésbicas e/ou trans que sequer se parecem; ou seja, o projeto evoca, evidencia e desarma a ferramenta heterossexualizante e cisgeneralizante do olhar normativo.

Um exemplo descritivo do modo de operação do chamado olhar heterocêntrico pode ser encontrado na história em quadrinhos intitulada Condições adversas de visibilidade (Figura 2) do fanzine Sapatoons \#2. ${ }^{5}$

O fanzine Sapatoons Queerdrinhos é um projeto colaborativo e autônomo de histórias em quadrinhos, piadas e jogos criado por e para pessoas trans, lésbicas, travestis e gays. Nessa publicação, tanto as histórias que enfocam vivências reais como as de caráter nitidamente ficcional expressam sentimentos, comportamentos, reflexões e desejos de subjetividades construídas desde as margens dos sistemas hegemônicos, o que atribui ao fanzine a função de arquivo e veículo de narrativas autorais queer.

O quadrinho Condições adversas de visibilidade representa uma vivência compartilhada por muitas subjetividades dissidentes: a história gira em torno da tensão, do medo e da vulnerabilidade de ser flagrado/a por uma figura de autoridade em um momento íntimo. O diferencial dessa experiência, no caso de gays, lésbicas, trans e travestis, é que, além do constrangimento da violação da intimidade, a situação tangencia os limites da segurança e da integridade, uma vez que as expressões de seus desejos são consistente e permissivamente punidas quando identificadas.

Esse quadrinho exagera os limites do olhar heterocêntrico e brinca com a margem de sua capacidade de identificação, assimilação e percepção da relação lésbica. A piada é estruturada através da exposição de duas faces contraditórias da invisibilização do desejo dissidente: a que é conveniente (o uso de um banheiro em comum, a liberdade para dormir na casa da "amiga", as demonstrações autorizadas de afeto entre "amigas" etc.) e a inconveniente (a deslegitimação da experiência lésbica que atribui inexistência).

No quadrinho, a reação de negação da mãe (que, apesar de flagrar sua filha com uma amante, é incapaz de reconhecer a lesbiandade latente da cena testemunhada) enfatiza o surpreendente poder do olhar heterocêntrico de editar, reinterpretar e normalizar o desejo e a subjetividade dissidentes. Entretanto, a resistência ou incapacidade da personagem de assimilar expressões visuais irrefutáveis de lesbiandade é ao mesmo tempo criticada e celebrada, uma vez que a narrativa da história remonta uma situação em que a invisibilidade pode evitar o constrangimento e as punições do flagrante.

No mesmo sentido, o projeto Pegadinha Les-Bi-Trans ${ }^{6}$ (Figura 3) dialoga especificamente com esse tipo de invisibilização sustentada pelo aparato cultural que reitera a improbabilidade da existência de lésbicas e pessoas trans (um possível efeito da marginalização de suas representações, escritos, produções etc.).

Desenvolvido por um efêmero agrupamento afetivo-político que inclui a presença das performers e amantes Mariana Zimmermann e Sabrina Lopes, o projeto fotográfico Pegadinha Les-Bi-Trans circula por listas de e-mail e redes feministas e pode ser descrito como uma espécie de ação performática urbana (embora não seja propriamente reivindicado como arte e se assemelhe mais a uma das pegadinhas de Silvio Santos). Na proposição, duas lésbicas se passam por turistas em grandes centros urbanos, selecionam aleatoriamente um/a transeunte e se aproximam com uma máquina fotográfica pedindo

\footnotetext{
${ }^{5} \mathrm{O}$ segundo volume do fanzine Sapatoons foi produzido no Brasil em novembro de 2013.

${ }^{6}$ A primeira versão desse projeto colaborativo foi elaborada em Curitiba em 2014 e contou com a participação das performers Mariana Zimmerman e Sabrina Lopes.
} 
que ele/ela tire uma foto delas. No momento do ato fotográfico (que é filmado por uma terceira pessoa), as proponentes se beijam inusitadamente.

Para executar essa divertida brincadeira, as performers selecionam um alvo relativamente aleatório (homens, mulheres, jovens, idosos, casais, mães etc.) que lhes pareça potencialmente heterossexual, pois a pegadinha funciona invertendo as premissas que orientam o olhar normativo. O potencial crítico do projeto começa a ser articulado com as reações instantâneas dos/as fotógrafos/as no momento do beijo: são elas que denunciam as ideologias e mecanismos invisibilizadores de seus olhares heterocêntricos. $O$ constrangimento (que obriga a pessoa a bater rapidamente a foto e evitar o contato visual), a sensação de ter sido insultado/a (geralmente acompanhada de comentário grosseiro) e a gargalhada (que denota surpresa e espanto) são as reações mais comuns e comprovam que os/as fotógrafos/as tinham uma expectativa (ou projeção) prévia e naturalizada concernente à sexualidade das performers.

A mencionada explicitação dos mecanismos do olhar heterocêntrico é complementada pela conivência do/a fotógrafo/a com a expressão de lesbiandade: tendo previamente aceitado bater a foto, a pessoa selecionada é de certa maneira conduzida e pressionada a olhar, enquadrar e fotografar (representar) uma cena raramente apresentada em público e comumente associada à perversão, à promiscuidade, à repulsa, ao abjeto e a outras formas de marginalidade.

Acredito que tanto a Pegadinha Les-Bi-Trans como a série Paralélicas têm intenções sombrias, negativas e desestabilizadoras, pois, em vez de plantar a sementinha do respeito e da igualdade nos corações dos seres humanos (para usar uma metáfora heterorreprodutiva), minam as engrenagens do olhar heterocêntrico introjetando nelas incerteza e insegurança. Esses projetos operam destreinando o olhar e induzindo a questionamentos acerca do gênero, da sexualidade e de muitos outros aspectos identitários que são geralmente inquestionados e naturalizados segundo a norma. Em outras palavras, devido a esse mecanismo de dubiedade, a figura de uma mulher, antes interpretada rigidamente e de antemão como feminina, heterossexual e cisgênero, passa a abrigar leituras contraditórias e incertas que recombinam transgeneridade e lesbiandade; ou seja, são propostas de descolonizações do olhar: desestabilizações na forma como se olha para os corpos, independentemente de como eles se apresentam.

Pode-se dizer que, no caso da Pegadinha Les-Bi-Trans, o que garante a desestabilização do olhar heterocêntrico e evita a assimilação e incorporação de lésbicas nas estruturas normativas de representação e percepção visual é a manutenção da marginalidade e do caráter nebuloso, negativo, amoral e violador que circunda a figura da lésbica: as performers (apesar de serem belas, brancas e femininas, obedecendo de certa forma os critérios e padrões normativos) não oferecem ao/à fotógrafo/a uma cena bela, romântica e sensual segundo a estética e os padrões que impulsionam o desejo heteronormativo. ${ }^{7}$

A pessoa encarregada da fotografia (uma espécie de espectador/a ativo/a, e não um voyeur) depara-se com um beijo de língua veementemente desajeitado, grosseiro, exagerado e satirizado, que jamais seria televisionado.

Diferentemente das reivindicações LGBTTQI, que apresentam uma figura aceitável, trabalhadora, digna de direitos e incorporada nos sistemas e aparatos ideológicos hege-

\footnotetext{
${ }^{7}$ Neste ensaio é apresentada uma versão cis-lésbica do projeto, mas vale dizer que a Pegadinha Les-Bi-Trans foi criada por pessoas trans e lésbicas masculinas e que sua concepção original produz efeitos diferentes daqueles aqui analisados. Em todo caso, a estrutura do projeto abriga uma variedade de subjetividades dissidentes e suas proponentes incentivam as múltiplas versões ou reproduções que o modelo da pegadinha pode incorporar.
} 
mônicos, as proposições aqui apresentadas tangenciam o tema da visibilidade atentando para o tênue limite entre existência e acomodação, incorporação ou assimilação. Nesse sentido, no caso da Pegadinha Les-Bi-Trans, a performance do beijo investe na repulsa para garantir a marginalidade da representação lésbica. Esse efeito é alcançado devido à interrupção das engrenagens dos prazeres visuais que normalmente orientam o olhar heterossexual, como o fetiche e o voyeurismo.

Essa preocupação com os prazeres visuais ${ }^{8}$ tem se manifestado constantemente em proposições representativas que enquadram figuras lésbicas. Um projeto que equilibra uma crítica incisiva à fetichização e "exotização" da dissidência e o desejo de assegurar seu espaço às margens das estruturas normativas aparece registrado no divertido vídeo Cazador Cazado, ${ }^{9}$ um projeto audiovisual independente de Alicia Murillo e do coletivo catalão Setas Feministas.

Trata-se de uma ação que ocorre em meio a uma manifestação pela libertação de gays, lésbicas, transexuais, transgêneros e bissexuais da Catalunha (possivelmente análoga às paradas do orgulho LGBTTTQ e caminhadas lésbicas brasileiras). O vídeo registra um grupo de ativistas que rodeia e fotografa ininterruptamente as pessoas que assistem, filmam e fotografam o protesto sem participar dele. Os/as proponentes gritam frases como "Olha! Heterossexuais! Existem!" e "Não me importa que tenham filhos! Vocês têm direito!" dirigindose aos/às espectadores/as, os/as quais se escondem e fogem constrangidos/as e surpresos/ as com a devolução do seu próprio olhar curioso, complacente, paternalista e fetichizante.

Nessa ação, os/as proponentes servem-se do recurso da inversão de papéis para evidenciar as assimetrias das estruturas naturalizadas dos sistemas e aparatos hegemônicos de produção de significado. ${ }^{10}$ Apesar de utilizar-se de um recurso vastamente empregado por artistas e coletivos feministas, como Barbara Kruger (série Help!), Mujeres Públicas (colagens do Proyecto heteronorma), Guerrilla Girls e muitos outros, seu tom negativo, irônico e ácido atribui originalidade à proposta e diferencia suas intenções daquelas comumente reivindicadas pelas populares manifestações e paradas LGBTTQI: enquanto ações menos anárquicas e separatistas demandam igualdade, assimilação e acomodação, a proposta em questão reforça a diferença e expressa o desejo de se manter fora das estruturas criadas, sustentadas e ocupadas pela norma. É seu tom negativo que exprime conflito, ofensa, ataque e repúdio e revela a rejeição de uma coalisão entre aqueles/as que assistem e aqueles/as que participam do protesto.

Essa carga negativa, de recusa e de desestabilização que se manifesta nos projetos Cazador cazado, Paralélicas e Pegadinha Les-Bi-Trans é uma das características distintas desses novos (ou outros) tipos de engajamento (artístico?), que estão deliberadamente situados às margens dos sistemas das artes e interconectados à dissidência e às subjetividades marginais. Contrastando com a positividade das estéticas, das reivindicações, dos discursos

\footnotetext{
${ }^{8} \mathrm{Em}$ seu artigo Visual Pleasure and Narrative Cinema, Laura Mulvey, uma das autoras pioneiras da teoria fílmica feminista, indica as relações entre o aparato cinematográfico e as assimetrias de gênero analisando o chamado "olhar masculino" (male gaze) e os processos de identificação dele derivado, os quais estão relacionados aos prazeres visuais (escopofilia, fetiche, voyeurismo etc.).

9 A ação Cazador Cazado foi elaborada por Alicia Murillo em parceria com o Coletivo Setas Feministas em 2013 em Barcelona.

${ }^{10} \mathrm{~J}$. Jack Halberstam aponta a eficácia da estratégia da inversão comentando, em seu livro Gaga Feminism, que preparou o curso de Introdução ao Gênero e à Sexualidade invertendo sua metodologia original: em vez de oferecer informações sobre gays, lésbicas, pessoas trans, intersexo etc., foi proposta uma análise da heterossexualidade vista do lado de fora, ou seja, sob um olhar de estranhamento. Segundo o autor, a desnaturalização da heterossexualidade mostrou-se mais efetiva que a demanda por tolerância às questões LGBTTI e queer.
} 
e das representações LGBTTQI, " os projetos apresentados neste ensaio manifestam o desejo dissidente de situar-se do lado de fora, de não se representar e de não se acomodar. Embora essa característica não se manifeste universal e rigorosamente na totalidade da produção da comunidade LGBTTQl, acredita-se que esse gesto antissocial está epistemologicamente vinculado à constituição das subjetividades dissidentes (lésbica, trans, travesti, gay etc.), sendo esse um dos elementos que formula o que Teresa De Lauretis chama de "sujeito excêntrico".

A autora, que dedicou grande parte de seu trabalho à obra de Monique Wittig e deu continuidade à ideia de que as lésbicas não são mulheres, coloca que

[...] a 'lésbica' formulada por Wittig não é simplesmente um indivíduo com uma 'preferência sexual' pessoal ou um sujeito social com uma prioridade 'política', mas um sujeito excêntrico constituído num processo de luta e interpenetração, uma reescrita do ser [...] em relação a uma nova compreensão de comunidade, de história, de cultura. ${ }^{12}$

Esse "sujeito excêntrico" (que escapa do gênero) constitui-se dentro de um espaço outro (elsewhere), onde uma série de prerrogativas originais surgem para orientar as estéticas, representações, ideologias, escritas, formas de relação e intenções e motivações de suas produções.

Um aspecto fundamental desse lugar-outro é sua característica falta de unidade e estabilidade, ou seja, sua capacidade de abarcar uma multiplicidade de contradições. Exemplificando essa ideia, De Lauretis assinala que a "sociedade lésbica" (separatista) originalmente concebida por Wittig

[...] não é um termo descritivo para um tipo de organização social (não-tradicional), nem um projeto para uma sociedade futurística, utópica ou distópica [...] Trata-se de um termo para um espaço conceitual e experiencial talhado fora do campo social, um espaço de contradições, no aqui e agora, que precisa ser afirmado mas não resolvido.

Uma versão mais contemporânea e talvez menos romantizada do "sujeito excêntrico" é apresentada por J. Jack Halberstam, que expande seu território (originalmente lésbico) para abrigar também outras subjetividades dissidentes (que ele chama de queer). A concepção do sujeito queer (gay, lésbico, trans, travesti, intersexo etc.) de Halberstam exalta o contraste entre centro e margem de forma a vincular a subjetividade "excêntrica" à marginalidade, à negatividade, à perda, ao fracasso, ao esquecimento, à descontinuidade e à falta de perspectivas de futuro. Pode-se dizer que Halberstam dissocia os projetos, a intenção e a estética das subjetividades queer da produção de significado humanitária e positiva e formula uma conexão entre dissidência e negatividade. Citando o trabalho de Lee Edelman (2005), o autor afirma que

\footnotetext{
"Como exemplo de proposta assimilacionista voltada às demandas de direitos LGBTTTQI, podemos citar o projeto fotográfico Eu te desafio a me amar, da artista Diana Blok (exposto no Inesc de Brasília), o FotografíalES, do coletivo Mujer \& Mujer em parceria com as Ativistas do Movimento Les-bi-trans Feminista de Guayaquil (exposto na FLACSO durante o I Colóquio Internacional Queer Interdisciplinar, Quito) e o The Queer Face de Milena Costa (exposto no Itaú Cultural de São Paulo).

${ }^{12}$ Teresa DE LAURETIS, 2007 p. 181, tradução nossa. Texto original: "Wittig's lesbian is not simply an individual with a personal "sexual preference" or a social subject with a "political" priority, but an eccentric subject constituted in a process of struggle and interpenetration, a rewriting of self $[\ldots]$ in relation to a new understanding of community, of history, of culture."

${ }^{13}$ DE LAURETIS, 2007, p. 181, tradução nossa. Texto original: "[...] not a descriptive term for a type of (nontraditional) social organization, nor a blueprint for a futuristic, utopian, or dystopian society [...] but rather the term for a conceptual and experiential space carved out of the social field, a space of contradictions, in the here and now, that need to be affirmed but not resolved."
} 
[...] o sujeito queer, conforme argumentado por Edelman, está epistemologicamente conectado à negatividade, ao sem-sentido, ao improdutivo e à ininteligibilidade, e em vez de lutar contra essa caracterização arrastando a dissidência para dentro do reconhecimento, ele [Edelman] propõe que abracemos a negatividade que, de qualquer forma, estruturalmente representamos.

Segundo o autor, a escolha pela negatividade, pela violação e pelo sombrio não passa de uma inversão da maneira de encarar preceitos praticamente intrínsecos às subjetividades dissidentes: Halberstam sugere que, em vez de abdicar a marginalidade e almejar o sucesso, a plenitude, a legitimidade, o direito e a normalização, muitas proposições de lésbicas, gays, transexuais, transgêneros e travestis assumem e acolhem o fracasso como prerrogativa e a margem como local de suas produções.

Apesar das diferenças estruturais entre o "sujeito excêntrico" (lésbico, livre e inclinado à alteridade) de De Lauretis e o "sujeito queer" (lésbico, trans, gay, travesti, interssexo e constituído desde a margem como expressão da negatividade) de Halberstam, pode-se dizer que ambas as propostas convergem celebrando e encorajando a receptividade de ser percebido e constituído como uma outra coisa (something else) - uma espécie de (des)tornar-se, (des)ser, (des)fazer, que abre caminho para outros modos, menos categóricos e estáveis, de representação e autorrepresentação.

Esse percurso, que relaciona a constituição de subjetividades dissidentes a formas novas e autônomas de produção e circulação de conhecimento e significado, parece sugerir uma autossuficiência queer que, em última instância, faz ressoar a obsolescência de, por exemplo, instituições e sistemas de arte e de ensino.

A preferência por alternativas menos lucrativas, populares, pretensiosas e abrangentes de circulação (como os fanzines, as ruas, as listas e redes de e-mails, os grupos de afinidade e os espaços autônomos) acompanha essas proposições autônomas e micropolíticas que assumem formas e investimentos menos inteligíveis, restritivos, fixos e categóricos de produção de conhecimento, significado e representação: podemos notar uma atual efervescência das temáticas lésbicas, trans, feministas, queer e de gênero (para ser mais genérica) nos eventos propostos em okupas (que têm abrigado desde debates sobre transfobia até proposições BDSM e pornoterroristas de performers como Leonor Silvestri e Missogina), nas ações gráficas e diretas executadas por coletivos afetivo-políticos, nas mostras de arte autogestionadas (como o Festival Lesbianarte ${ }^{15}$ ) e em encontros feministas independentes brasileiros (Encontrada, Korpus Krisis, Festival Vulva la Vida, Suspirin Feminista Antifest e muitos outros).

Também nesse sentido é importante ressaltar a multiplicação de material autônomo e fanzines contendo traduções de textos que abarcam a temática das subjetividades dissidentes (como os escritos por Monique Wittig, Beatriz Preciado e Jack Halberstam, entre outros) ou de projetos autorais independentes, de domínio público e sem fins lucrativos, como é o caso do Ofensivo Trans (poesias e escritos de homens trans-maricas), Heterotipos (fotos de dragkings), Sintomas (poesia trans de Michel Riquelme), Viva la Redesconstrucción Vaginal (um relato escrito e fotográfico sobre masculinidade lésbica e trans), Dramas Pobres e Cuerpos para Odiar (textos e poesias travestis compiladas e escritas por Cláudia Rodriguez),

14 Jack [Judith] HALBESTAM, 2011, p. 106, tradução nossa. Original em inglês: "[...] the queer subject, he argues, has been bound epistemologically to negativity, to nonsense, to antiproduction, and to unintelligibility, and instead of fighting this characterization by dragging queerness into recognition, he proposes that we embrace the negativity that we anyways structurally represent."

${ }^{15}$ O Festival Lesbianarte é um encontro anual autogestionado que organiza exposições, workshops, debates e outras atividades focadas em temáticas lésbicas. O evento teve sua primeira edição em 2013 no México D.F. 
Lenguaraz e Chonguitas (poesia lésbica e relatos de masculinidades lésbicas, de Valéria Flores e Fabi Tron), Gorda, eu?! (texto, colagem e desenho sobre gordura negra e lésbica, de Tatiana Nascimento), Transtorno de Anomalin (montagem de textos e fotografias sobre a coerência da identidade trans), Poemário Trans Pirado (poesia da performer travesti Susy Shock), Monstrans: experiências com horrormônios (relatos trans-escritos e des(d)enhados em primeira pessoa), Sapatoons Queerdrinhos e muitos outros.

Talvez essa guinada dissidente rumo ao fracasso e à autonomia explique o paradoxo entre o crescimento do número de manadas político-afetivas e de proposições (piadas, jogos, brincadeiras, manifestações, fanzines etc.) les-bi-trans-feministas latino-americanas e caribenhas e o hiato das exposições de arte política engajada feminista e/ou queer nas galerias e museus.

\section{Conclusão}

Neste ensaio, sugeriu-se que, ao propor a desestabilização de um olhar heterocêntrico e, ao mesmo tempo, evitando representações idealistas, estereotipadas ou "verdadeiras" de lesbiandade, os projetos Paralélicas e Pegadinha Les-Bi-Trans apontam possibilidades sem nomeá-las, gesticulam novas formas de revolta sem prescrevê-las e privilegiam a recusa e a destruição em detrimento da aquisição e da criação.

Essas publicações, que raramente serão encontradas nas feiras de fanzines das instituições autorizadas, assim como outras proposições (brincadeiras, pegadinhas, performances e pichações), que dificilmente aparecerão nas bienais, mantêm propositadamente os conhecimentos, as experiências e os significados dissidentes à margem do inteligível e do normal. Suas e seus proponentes (lésbicas, giletonas, trans, gays, travestis e outras interseções) acolhem o fracasso como prerrogativa, pois conhecem os benefícios e prazeres inesperados que uma perspectiva separatista e não assimilacionista pode proporcionar.

Essa forma sombria, nômade, incerta e negativa de constituir-se e representar-se (o não ser, o (des)fazer e o (des)tornar) manifesta-se num lugar-outro (elsewhere), que é anunciado, porém nunca inteiramente formulado justamente porque não deve tomar forma ou estrutura completamente estáveis. Nesse lugar-outro, os significados ainda não estão suficientemente rígidos e fixos e podem deslizar com alguma flexibilidade para criar outras formas de relação, afeto, conhecimento e existência que, ocasionalmente, se manifestam como aparições marginais assombrosas e tocam o centro para corrompê-lo e contaminá-lo, embora recusando a intenção de ocupá-lo.

\section{Referências}

CAZADOR cazado. Direção: Alicia Murillo e Coletivo Setas Feministas. [2014]. 1h57min, color. Disponível em: <https://www.youtube.com/watch?v=xrV-yNwv2ag\&hd=1 > . Acesso em: 12 ago. 2014

DE LAURETIS, Teresa. Alice doesn't. Bloomington: Indiana University Press, 1984. Figures of resistance. Chicago: University of Illinois Press, 2007.

HALBERSTAM, Jack [Judith]. Gaga feminism. Boston: Beacon Press, 2012. . The queer art of failure. London: Duke University Press, 2011.

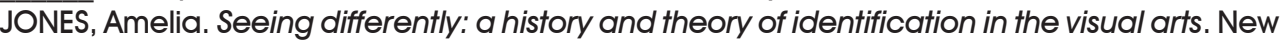
York: Routlegde, 2012.

MULVEY, Laura. "Visual pleasure and narrative cinema". Screen, Oxford, v. 16, n. 3, p. 6-18, Autumn 1975.

POLLOCK, Griselda. Vision and difference. New York: Routledge, 1988.

WITTIG, Monique. The straight mind and other essays. Boston: Beacon Press, 1992. 
[Recebido em outubro de 2014 e aceito para publicação em novembro de 2014]

Trans-Lesbianizing the Gaze: Representations Posed on the Edge of Art

Abstract: By reclaiming failure, inadequacy, marginality and negativity as distinctive characteristics of queer projects and queer subjective constructions, this essay suggests that there is a marginal lesbian/trans imaginary being formulated within the counter-artistic Brazilian projects entitled "Pegadinha Les-Bi-Trans", "Sapatoons Queerdrinhos" and "Eu vejo lésbicas em todos os lugares". By analyzing the subversive potentials imposed by negative and post-identity based auto-representative strategies employed within autonomous projects located in the borders of the authorized institutions of knowledge production (such as the art systems), I analyze the creation of a translesbianizing gaze, which is able to destabilize heterocapitalistic rhetorics and visualities.

Key Words: Queer Art; Representation; Lesbian; Transgender; Marginality. 